\title{
Epidemic investigations within an arm's reach - role of google maps during an epidemic outbreak
}

\author{
Roman Sonkin $^{1}$ (D) Evan Avraham Alpert ${ }^{2}$ (D) Eli Jaffe $^{1}$ (D) \\ Received: 9 April 2020 / Accepted: 7 July 2020 / Published online: 12 July 2020 \\ (C) IUPESM and Springer-Verlag GmbH Germany, part of Springer Nature 2020
}

\begin{abstract}
Epidemics such as novel Coronavirus 2019 (COVID-19) can be contained and the rate of infection reduced by public health measures such as epidemiologic inquiries and social distancing. Epidemiologic inquiry requires resources and time which may not be available or reduced when the outbreak is excessive. We evaluated the use of Google Maps Timeline (GMTL) for creating spatial epidemiologic timelines. The study compares locations, routes, and means of transport between GMTL and user recall for 17 suitable users who were recruited during March 2020. They were interviewed about their timeline using the Timeline Follow-Back (TLFB) method which was then compared to their GMTL and discrepancies between both methods were addressed. Interviewer conclusions were divided into categories: (1) participant recalled, (2) no recall (until shown). Categories were subdivided by GMTL accuracy: [a] GMTL accurate, [b] GMTL inaccurate, [c] GMTL data missing. A total of 362 locations were compared. Participants recalled $322(88.95 \% \mathrm{SD}=8.55)$ locations compared with $40(11.05 \%, \mathrm{SD}=2.05)$ locations not recalled. There were 304 locations found accurate on GMTL (83.98\%, SD =9.49), $29(8.01 \%, \mathrm{SD}=1.11)$ inaccurate locations, and $29(8.01 \%, \mathrm{SD}=0.54)$ missing locations. The total discrepancy between GMTL and TLFB recall was 95 cases $(26.24 \%, \mathrm{SD}=3.25)$. Despite variations between users, Google Maps with GMTL technology may be useful in identifying potentially exposed individuals in a pandemic. It is especially useful when resources are limited. Further research is required with a larger number of users who are undergoing a real epidemiologic investigation to corroborate findings and establish further recommendations.
\end{abstract}

Keywords COVID19 $\cdot$ Spatial epidemiology $\cdot$ Pandemics $\cdot$ Epidemics

\section{Introduction}

Epidemics are defined as the occurrence of a group of illnesses of similar nature, in a community or region, of more than normal expectancy, and derived from a common or a propagated source. Pandemics refer to epidemics that affect the world globally [1]. In addition to severe illness and death, pandemic diseases cause fear and economic instability [2].

This article is part of the COVID-19 Health Technology: Design, Regulation, Management, Assessment

Roman Sonkin

romans@mda.org.il

Community Division, Magen David Adom, Tel Aviv-Jaffo, Israel

2 Department of Emergency Medicine, Shaare Zedek Medical Center, Jerusalem, Israel
In December 2019 a novel Coronavirus 2019 (COVID-19) outbreak began in Wuhan in the Hubei region of China and very quickly spread worldwide, ultimately becoming recognized by the World Health Organization (WHO) as a pandemic [3]. COVID-19 is highly contagious with a median incubation period of 4 days, with the most common symptoms being fever and cough. Other symptoms include fatigue, headache, diarrhea, hemoptysis, dyspnea, and pneumonia $[4,5]$.

One of the traditional and widely used methods for the assessment of the extent of an epidemic outbreak is the epidemiologic investigation. This is usually conducted by health authorities by interviewing the suspected or confirmed exposed individuals. Depending on available time and resources, this may include an examination of evidence such as receipts and photographs. It is then followed by decisions and actions based on the investigation findings [6]. It may lead to either local or general containment measures in cases of a communicable disease outbreak and allows the notification of potentially exposed persons and locations [7, 8]. Inquiries by interview, being the main investigatory technique, are based on self-recall, thus making them prone 
to error [9]. Accuracy of recall depends among other things upon one's cognitive abilities, questioning environment, and levels of stress which may be significant during an investigation $[10,11]$.

A transmission dynamics analysis may improve understanding of the epidemiologic factors of the disease and allow monitoring of the effectiveness of measures taken to control the outbreak [12-14]. Hellewell and colleagues used the stochastic transmission model to show that in most scenarios, highly effective contact tracing and case isolation is enough to control a new outbreak of COVID-19 within three months. The probability of control decreases with the prolonged delay between symptom onset to isolation, fewer cases ascertained by contact tracing, and increasing transmission before symptoms [15]. Geographic Information Systems (GIS) are not a new concept in both epidemiologic research and inquiries during an epidemic may contribute to understanding transmission dynamics [16]. GIS has been used to allow visual surveillance on trends, pathogens, diseases, and potential outbreaks $[17,18]$. When it is used for epidemiologic inquiries it is usually uploaded manually by the investigator $[19,20]$. Firestone et al. showed that combining spatial analysis with social network analysis enhances the quality of epidemic investigations [21]

Since the previous pandemic of H1N1 in 2009 which infected over 250,000 persons [22-24] smartphone positioning technologies have become more accurate due to several factors including improved precision of integrated GPS antennas, improved cellular support location services in the newer generations of cellular networks [25], and better integration with phone sensor data such as an accelerometer, social networks, and Wi-Fi connectivity. Google Maps is the most popular among the maps applications and the fourth most used app in the United States [26]. Google Maps allows continuous tracking of places that one has traveled including walking, biking, public transportation, car, and airline travel on a timeline-Google Maps Timeline (GMTL) [27]. The GMTL is not activated by default, rather the user is prompted to activate it when the android phone is initiated, or when the Google Maps app is installed on another phone (e.g. iPhone by Apple). GMTL data may be exported as a Keyhole Markup Language (KML) file containing GPS coordinates and GMTL radius of accuracy around the given location (in meters). Keyhole Markup Language (KML) was adopted as an Open Geospatial Consortium implementation standard [28]

The objective of this paper is to compare the accuracy of GMTL and user recall during routine events as a surrogate for examining the role of Google Maps in epidemiologic inquiries during pandemic outbreaks.

\section{Methods}

This study compared locations, routes, and means of transportation including walking, car, biking, public transportation, and airline travel between GMTL and user recall. The 17 Google Maps users whose timeline was activated were recruited through posts on "Facebook" published during the second week of March 2020. All participants were questioned in the same week by the same interviewer. They were informed that no personal information will be stored or published and that sharing their GMTL is regarded as consent to participate in the study. The study was conducted in Haifa, Israel which has a diverse population in terms of age, religion, and socioeconomic status.

Self-reporting is prone to error but to a lesser degree when done face to face with an interviewer [29,30]. For this reason, a previously validated tool was used- the Timeline FollowBack (TLFB) method. This was first established for research on substance use where reliable and valid measures were sought for self-reports on use and abuse of alcohol and other substances [31-35], smoking behavior [36]' eating disorders [37], sexual behavior [38-41], and overnight locations of homeless people [42] The TLFB method is based on Tourangeau's methods for improving autobiographical memory recall: (1) taking more time to remember, (2) breaking down a class of events into subclasses, (3) recalling in reverse chronology, and (4) using landmarks [43].

Five types of data were defined to be sought through both GMTL and TLFB methods: locations, routes, means of transportation, times, and durations. The interview began with an outline of the routine daily schedule for each participant to be used as memory landmarks. A timeline was then constructed in a reverse fashion containing visited locations, routes, means of transportation, times, and durations in the day that occurred two days before conducting the interview. This was then validated in the chronological order of the day (i.e. from earlier to later events). Each participant's GMTL was then examined and both TLFB and GMTL data were inserted into an Excel Spreadsheet (Redmond, WA, USA: Microsoft). Each participant was shown the discrepancies between GMTL and TLFB data. Conclusions were divided by the interviewer into two categories based on user recall: (1) participant recalled or (2) no recall until shown. Categories were subdivided by GMTL accuracy: [a] GMTL accurate, [b] GMTL inaccurate, [c] GMTL data missing.

Locations and means of transportation were collectively summed to allow better statistical comparison as the endpoint of the study is location accuracy and not number of accurate timelines.

\section{Results}

Demographics: All 17 participants are citizens of Israel and their Google Maps interface is in Hebrew. A total of 9 $(41.17 \%)$ were males, with a mean age of $29(\mathrm{SD}=5)$. Public transportation as a sole means of transportation was 
used by $7(41.17 \%)$ of the participants compared to 6 (35.29\%) who used only a car. Both means of transport were used by 3 of the participants (17.64\%).

A total of 362 locations were compared. Participants recalled $322(88.95 \% \mathrm{SD}=8.55)$ locations, compared with $40(11.05 \%, \mathrm{SD}=2.05)$ locations that they did not recall. There were $303(83.70 \%, \mathrm{SD}=9.5)$ locations found accurate on GMTL compared with $30(8.29 \%, \mathrm{SD}=1.16)$ inaccurate locations. GMTL had $29(8.01 \%, \mathrm{SD}=1.84)$ missing locations. The total discrepancy between GMTL and TLFB recall was 95 cases $(26.24 \%, \mathrm{SD}=3.26)$. There were $26(7.18 \%$, $\mathrm{SD}=1.24)$ locations that the participants recalled but were found inaccurate on the GMTL, 29 locations that participants recalled but were missing from their GMTL, 36 (9.94\%, SD = 2.52) locations that the participants did not recall until shown their timeline which were confirmed as accurate, and 4 $(1.10 \%, \mathrm{SD}=0.54)$ locations that the participants did not recall until shown their timeline and were found inaccurate (Figs. 1 and 2).

\section{Discussion}

Rodriguez and colleges examined the potential use of GMTL as evidence for judicial purposes, by quantifying its accuracy compared to a GPS device with superior accuracy, but did not find Google Maps accurate enough for use in forensics. However, that study did not examine the use of the fourth generation network which is widely used in mobile networks in Israel [44]. In addition, this study compared the traditional epidemiologic inquiry which is based on memory recall to the same users GMTL while the study by Rodriguez compared coordinates to a GPS device of better accuracy. Other studies related to epidemics have used static locations which were either uploaded automatically by the use of third-party applications or manually by a researcher. In addition, these were pre-decided locations such as home, work, etc. Unlike this study, they did not use the dynamic daily timeline to track the exact visited places $[17,45,46]$.

The GMTL accuracy of $83.98 \%$, means that 84 of 100 visited places, buses, cars, and streets are documented correctly and can be used in epidemiologic inquiries without further processing. The users did not recall $11.05 \%$ of the locations, but when reminded by GMTL they found that $90 \%(n=36)$ of those locations were accurate and $10 \%(n=4)$ were inaccurate locations but were found to be useful as an aid to recall the correct location. GMTL also provided accurate times and thus durations of stay and transport in comparison with times and durations recalled by users which were crude estimations or based on their regular schedule not accounting for daily changes.

In the first month of the COVID-19 outbreak in Israel, the exposure potentials of the first 100 patients varied between 100 for a passenger returning home on a small flight from an endemic country and 4400 for a boy infected in a store who then went to watch a sports game in a stadium [47]. During the evolution of a pandemic, the case capacity increases and resources become less and less available to conduct individual epidemiologic investigations. This point in time differs between countries and the availability of resources. In these cases, an exposed or confirmed positive user may be asked to export a KML file from GMTL and upload it to a dedicated platform for automation of the epidemiologic inquiries. It is important to note that the file may technically be stripped of personal identifying data by either the user or the authorities. This may have a positive impact concerning privacy as there will be no identifying details linked to the locations but negative value if the authorities need to contact the user in cases such as when they need to be in quarantine.

In the earliest stages of epidemic evolution and as preparation, an official recommendation of health organizations should be to turn on the GMTL feature of one's smartphone. Currently, in most countries, adherence to quarantine is not routinely monitored unless there is a specific complaint filed
Fig. 1 Flow chart depicting accuracy of location according to GMTL

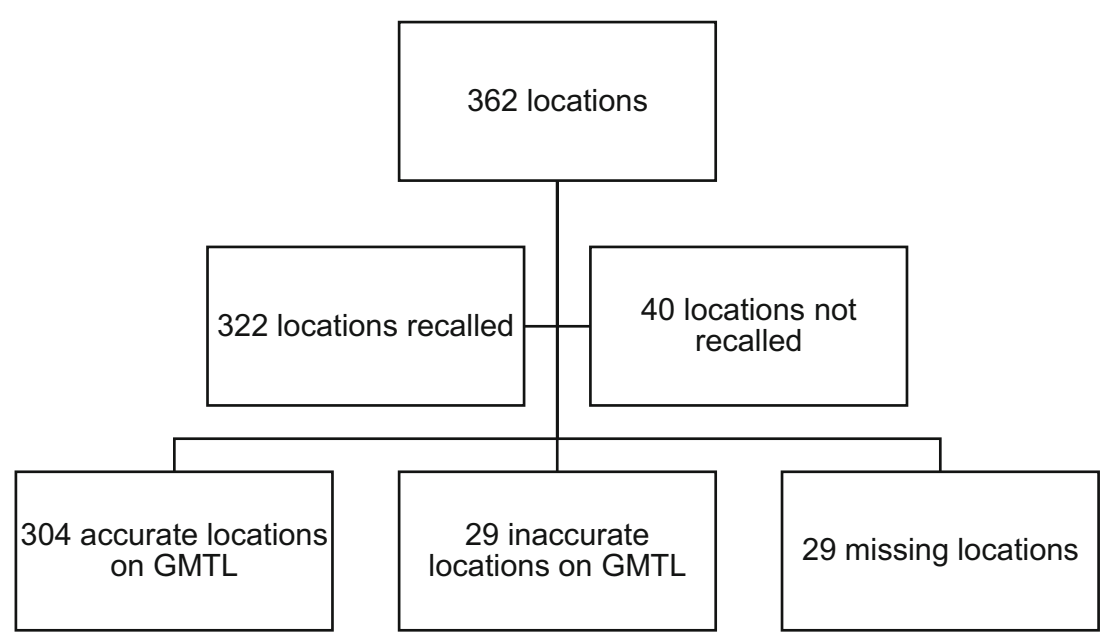


Fig. 2 Flow chart depicting the discrepancies between GMTL and TLFB

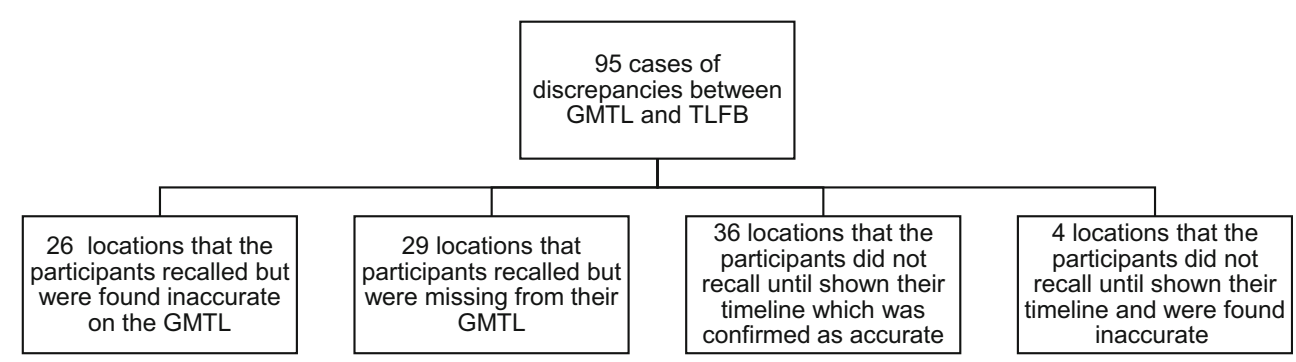

with law enforcement. Privacy is a basic human right and is therefore a subject of public discussion, legislation, and enforcement, although the level of awareness and extent that people trust in peers, companies and authorities varies greatly between countries [48]. In some countries alongside meticulous legislation, health and privacy laws contain exceptions concerning public health in and communicable diseases to protect the majority [49]. Violation of this right should be considered carefully and repeatedly by a panel of experts such as an ethics committee [50]. Public health concerns during an epidemic might tip the balance between the right for privacy and enforcing adherence to quarantine or informing of other exposed persons. A possible obstacle to this might be a reluctance to cooperate. In these cases, possible options are confiscation of the information under the law upon review by an ethics committee or direct acquisition of data from Google depending on the laws and regulations of the country.

The COVID-19 pandemic has motivated the development of dedicated applications and tools for use by health authorities as well as private users. Currently these solutions are mostly based on standalone platforms. In the future, GMTL may be used as complementary to these solutions or even possibly linked to these applications through the user's smartphone.

\subsection{Limitations}

There are several limitations to this study. This was a study of participants recruited from a Facebook advertisement who were healthy and not actually exposed or potentially exposed to any infectious material. The number of participants in this study was low due to difficulty in recruiting, and true objective location history cannot be obtained. In addition, this would only apply to countries where the majority of citizens have GTML on their telephones. It may not apply to areas where people do not possess newer generation smartphones or where newer cellular technologies are not implemented. In Israel, thousands of ultra-orthodox citizens do not have this feature on their telephones for religious reasons.

\section{Conclusion}

Google maps with GMTL technology may be useful in identifying potentially exposed individuals in a pandemic. Further research is required with a larger number of users during a real infectious outbreak to corroborate findings and establish further recommendations.

Authors' contributions Roman Sonkin conducted the questioning and collected the data.

All other aspects of the research and manuscript preparation were shared equally between researchers.

Data availability The excel spreadsheet can be supplied upon request.

\section{Compliance with ethical standards}

Conflicts of interest/competing interests Non declared.

Ethics approval Not applicable.

Consent to participate Not applicable.

Consent for publication Not applicable.

Conflict of interest The authors declare that they have no competing of interests.

\section{References}

1. Celentano DD, Szklo M, Gordis L. The dynamics of disease transmission. Gordis Epidemiol. 6th Editio. Philadelphia, PA: Elsevier; 2018. p. 23-26.

2. Elmore JG, Wild DMG, Nelson HD, et al. Investigation of epidemics. Jekel's Epidemiol. Biostat. Prev. Med. Public Heal. 5th Editio. St. Louis, Missouri: Elsevier; 2020. p. 35-54.

3. Coronavirus disease 2019 (COVID-19) - Situation report 51 [Internet]. Geneva; 2020 [cited 2011 Mar 19]. Available from: https://www.who.int/docs/default-source/coronaviruse/situationreports/20200311-sitrep-51-covid-19.pdf?sfvrsn=1ba62e57 10.

4. Guan W-J, Ni Z-Y, Hu Y, et al. Clinical characteristics of coronavirus disease 2019 in China. N Engl J Med [Internet]. 2020; Available from: http://www.ncbi.nlm.nih.gov/pubmed/32109013.

5. Adhikari SP, Meng S, Wu Y-J, et al. Epidemiology, causes, clinical manifestation and diagnosis, prevention and control of coronavirus disease (COVID-19) during the early outbreak period: a scoping review Infect Dis Poverty [Internet]. 2020;9:29. Available from: https://doi.org/10.1186/s40249-020-00646-x.

6. Goodman RA, Buehler JW, Koplan JP. The epidemiologic field investigation: science and judgment in public health practice. Am J Epidemiol. [Internet]. 1990 [cited 2020 May 8];132:9-16. Available from: https://academic.oup.com/aje/article/77979/THE.

7. National Stratery For Pandemic Influenza - Implementation Plan [Internet]. Washington; 2006 [cited 2020 May 8]. Available from: 
https://www.cdc.gov/flu/pandemic-resources/pdf/pandemicinfluenza-implementation.pdf.

8. Holloway R, Rasmussen SA, Zaza S, et al. Updated preparedness and response framework for influenza pandemics [Internet]. 2014 [cited 2020 May 8]. Available from: https://www.cdc.gov/mmwr/ preview/mmwrhtml/rr6306a1.htm.

9. Kelly P, Doherty A, Mizdrak A, Marshall S, Kerr J, Legge A, et al. High group level validity but high random error of a self-report travel diary, as assessed by wearable cameras. J Transp Heal. 2014;1:190 201.

10. Camos V, Portrat $\mathrm{S}$. The impact of cognitive load on delayed recall. Psychon Bull Rev. 2015;22:1029-34.

11. Deffenbacher KA, Bornstein BH, Penrod SD, McGorty EK. A meta-analytic review of the effects of high stress on eyewitness memory. Law Hum Behav. 2004;28:687-706.

12. Camacho A, Kucharski A, Aki-Sawyerr Y, et al. Temporal changes in ebola transmission in Sierra Leone and implications for control requirements: a real-time modelling study. PLoS Curr. [Internet]. 2015;7:ecurrents.outbreaks.406ae55e83ec0b5193e30856b9235e. Available from: https://pubmed.ncbi.nlm.nih.gov/25737806.

13. Funk S, Ciglenecki I, Tiffany A, et al. The impact of control strategies and behavioural changes on the elimination of Ebola from Lofa County, Liberia. Philos. Trans. R. Soc. B Biol. Sci. [Internet]. 2017;372:20160302. Available from: https://doi.org/10. 1098/rstb.2016.0302

14. Riley S, Fraser C, Donnelly CA, et al. Transmission dynamics of the etiological agent of SARS in Hong Kong: impact of public health interventions. Science (80-. ). [Internet]. 2003;300:1961 LP - 1966. Available from: http://science.sciencemag.org/content/300/ 5627/1961.abstract.

15. Hellewell J, Abbott S, Gimma A, et al. Feasibility of controlling COVID-19 outbreaks by isolation of cases and contacts. Lancet Glob. Heal. [Internet]. 2020; Available from: https://doi.org/10. 1016/S2214-109X(20)30074-7.

16. Clarke KC, McLafferty SL, Tempalski BJ. On epidemiology and geographic information systems: a review and discussion of future directions. Emerg Infect Dis [Internet]. 1996;2:85-92 Available from: https://pubmed.ncbi.nlm.nih.gov/8903207.

17. Carroll LN, Au AP, Detwiler LT, et al. Visualization and analytics tools for infectious disease epidemiology: A systematic review. J Biomed Inform. [Internet]. 2014;51:287-298. Available from: http://www.sciencedirect.com/science/article/pii/ S1532046414000914.

18. Paul E, Daniel W. Spatial epidemiology: current approaches and future challenges. Environ Health Perspect [Internet]. 2004;112: 998-1006. Available from: https://doi.org/10.1289/ehp.6735.

19. Wang Y, Tian G-B, Zhang R, Shen Y, Tyrrell JM, Huang X, et al. Prevalence, risk factors, outcomes, and molecular epidemiology of mcr-1-positive Enterobacteriaceae in patients and healthy adults from China: an epidemiological and clinical study. Lancet Infect Dis [Internet]. 2017;17:390-9 Available from: http://www. sciencedirect.com/science/article/pii/S1473309916305278.

20. Aanensen DM, Huntley DM, Feil EJ, al-Own F', Spratt BG. EpiCollect: linking smartphones to web applications for epidemiology, ecology and community data collection. PLoS One [Internet]. 2009;4:e6968-8 Available from: https://pubmed.ncbi. nlm.nih.gov/19756138.

21. Firestone SM, Christley RM, Ward MP, Dhand NK. Adding the spatial dimension to the social network analysis of an epidemic: investigation of the 2007 outbreak of equine influenza in Australia. Prev Vet Med [Internet]. 2012;106:123-35 Available from: http://www.sciencedirect. com/science/article/pii/S0167587712000384.

22. Zarocostas J. World Health Organization declares A (H1N1) influenza pandemic. BMJ [Internet]. 2009;338:b2425. Available from: http://www.bmj.com/content/338/bmj.b2425.abstract.
23. McCallum L, Partridge J. Epidemiological characteristics of the influenza $\mathrm{A}(\mathrm{H} 1 \mathrm{~N} 1) 2009$ pandemic in the Western Pacific Region. West. Pacific Surveill. response J. WPSAR [Internet]. 2010;1:5-11. Available from: https://pubmed.ncbi.nlm.nih.gov/ 23908874

24. Dawood FS, Iuliano AD, Reed C, et al. Estimated global mortality associated with the first 12 months of 2009 pandemic influenza A H1N1 virus circulation: a modelling study. Lancet Infect. Dis. [Internet]. 2012;12:687-695. Available from: http://www. sciencedirect.com/science/article/pii/S1473309912701214.

25. Campos RS. Evolution of positioning techniques in cellular networks, from $2 \mathrm{G}$ to $4 \mathrm{G}$. Femminella M, editor. Wirel. Commun. Mob. Comput. [Internet]. 2017;2017:2315036. Available from. https://doi.org/10.1155/2017/2315036.

26. Wurmser Y. Maps and navigation apps discovery, exploration features open up ad opportunities [Internet]. 2018. Available from: https://www.emarketer.com/content/maps-and-navigation-apps.

27. Google Maps Timeline - Google maps help [Internet]. [cited 2020 Mar 22]. Available from: https://support.google.com/maps/answer/ $6258979 ? \mathrm{co}=$ GENIE.Platform\%3DDesktop\&hl=en.

28. OGC® Standards - KML [Internet]. Wayland, MA; [cited 2020 Mar 18]. Available from: https://www.ogc.org/standards/kml.

29. Bradburn NM. Temporal representation and event dating. 1999;61-74.

30. Barsky AJ. Forgetting, fabricating, and telescoping: the instability of the medical history. Arch Intern Med. 2002;162:981-4.

31. Sobell LC, Maisto SA, Sobell MB, Cooper AM. Reliability of alcohol abusers' self-reports of drinking behavior. Behav Res Ther. 1979;17:157-60.

32. Sobell MB, Sobell LC, Klajner F, Pavan D, Basian E. The reliability of a timeline method for assessing normal drinker college students' recent drinking history: utility for alcohol research. Addict Behav. 1986;11:149-61.

33. Sobell LC, Sobell MB. Timeline follow-back. Meas. Alcohol Consum. Humana Press; 1992. p. 41-72.

34. Searles JS, Helzer JE, Walter DE. Comparison of drinking patterns measured by daily reports and timeline follow back. Psychol Addict Behav. 2000;14:277-86.

35. SACKS JAY, DRAKE RE, WILLIAMS VF, et al. Utility of the time-line follow-back to assess substance use among homeless adults. J Nerv Ment Dis [Internet]. 2003 [cited 2020 Mar 15];191: 145-153. Available from: http://journals.lww.com/00005053200303000-00002.

36. Brown RA, Burgess ES, Sales SD, Whiteley JA, Evans DM, Miller IW. Reliability and validity of a smoking timeline follow-back interview. Psychol Addict Behav. 1998;12:101-12.

37. Bardone AM, Krahn DD, Goodman BM, Searles JS. Using interactive voice response technology and timeline follow-back methodology in studying binge eating and drinking behavior: different answers to different forms of the same question? Addict Behav [Internet]. 2000;25:1-11 Available from: http://www. sciencedirect.com/science/article/pii/S0306460399000313.

38. Midanik LT, Hines AM, Barrett DC, Paul JP, Crosby GM, Stall RD. Self-reports of alcohol use, drug use and sexual behavior: expanding the timeline follow-back technique. J Stud Alcohol. 1998;59:681-9.

39. Weinhardt LS, Carey MP, Maisto SA, et al. Reliability of the Timeline follow-Back sexual behavior interview. Ann Behav Med [Internet]. 1998;20:25-30. Available from: https://doi.org/ 10.1007/BF02893805

40. Carey MP, Carey KB, Maisto SA, et al. Assessing sexual risk behaviour with the Timeline Followback (TLFB) approach: continued development and psychometric evaluation with psychiatric outpatients. Int J STD AIDS [Internet]. 2001 [cited 2020 Mar 15];12: 365-375. Available from: http://www.ncbi.nlm.nih.gov/pubmed/ 11368817. 
41. Nelson WA, Clum GA. Assessment of panic frequency: reliability and validity of a time-line follow-back method. J Psychopathol Behav Assess. 2002;24:47-54.

42. Tsemberis S, McHugo G, Williams V, Hanrahan P, Stefancic A. Measuring homelessness and residential stability: the residential timeline follow-back inventory. J Community Psychol. 2007;35:29-42.

43. Tourangeau R. Remembering what happened: Memory errors and survey reports. The science of self-report. Implications for research and practice (pp. 29-48). Lawrence Erlbaum Associates; 2000.

44. Macarulla Rodriguez A, Tiberius C, van Bree R, Geradts Z. Google timeline accuracy assessment and error prediction. Forensic Sci Res. 2018;3:240-55.

45. Gehlen M, Nicola MRC, Costa ERD, Cabral VK, de Quadros ELL, Chaves CO, et al. Geospatial intelligence and health analitycs: its application and utility in a city with high tuberculosis incidence in Brazil. J Infect Public Health. 2019;12:681-9.

46. Poojar B, Shenoy KA, Naik PR, et al. Spatiotemporal analysis of drug-resistant TB patients registered in selected districts of Karnataka, South India: a cross-sectional study. Trop. Med. Health [Internet]. 2020 [cited 2020 Mar 30];48:15. Available from: https://tropmedhealth.biomedcentral.com/articles/10.1186/s41182020-00199-7.

47. Basson E. Israel Ministry of Health Press Reslease [Internet]. Jerusalem; 2020 [cited 2020 Mar 18]. Available from: https:// www.health.gov.il/English/Topics/Diseases/corona/Pages/pressrelease.aspx.

48. Thakkar V, Gordon K. Privacy and policy implications for big data and health information technology for patients: a historical and legal analysis. ITCH. 2019. p. 413-417.

49. Coleman MP, Evans BG, Barrett G. Confidentiality and the public interest in medical research - will we ever get it right? Clin. Med. (Northfield. Il). [Internet]. 2003;3:219 LP - 228. Available from: http://www.rcpjournals.org/content/3/3/219.abstract.

50. Human Rights | United Nations [Internet]. [cited 2020 Mar 16]. Available from: https:/www.un.org/en/sections/issues-depth/ human-rights/.

Publisher's note Springer Nature remains neutral with regard to jurisdictional claims in published maps and institutional affiliations. 